\title{
Brief Experimental Analysis of Combining Stimulus Change with Consequences to Improve Oral Reading Fluency and Accuracy
}

\author{
Meghan Ferraro1, Amanda Smith2, Edward Snyder1, \\ Cristin Leahy ${ }^{3}$, Kaylee Cavanah ${ }^{1}$ \\ ${ }^{1}$ Edinboro University, Edinboro, PA, USA \\ ${ }^{2}$ Carlow University, Pittsburgh, PA, USA \\ ${ }^{3}$ Clarion University, Clarion, PA, USA \\ Email: ferrarom@edinboro.edu
}

How to cite this paper: Ferraro, M., Smith, A., Snyder, E., Leahy, C., \& Cavanah, K. (2021). Brief Experimental Analysis of Combining Stimulus Change with Consequences to Improve Oral Reading Fluency and Accuracy. Psychology, 12, 1944-1959. https://doi.org/10.4236/psych.2021.1212118

Received: November 5, 2021

Accepted: December 7, 2021

Published: December 10, 2021

Copyright $\odot 2021$ by author(s) and Scientific Research Publishing Inc. This work is licensed under the Creative Commons Attribution International License (CC BY 4.0).

http://creativecommons.org/licenses/by/4.0/ (c) (i) Open Access

\begin{abstract}
The purpose of this brief experimental analysis was to examine the effect of changes in visual stimuli, contingent reinforcement, and/or performance feedback on oral reading fluency skills of seven students at-risk of reading failure in second and third grade. Specifically, the current study examined how font size, contingent reinforcement, performance feedback, and combination of font size, contingent reinforcement, and performance feedback affect readability and ultimately, students' reading fluency performance. For six participants, adding the element of performance feedback or adding the elements of both performance feedback and contingent reinforcement increased their words correct per minute (WCPM). For five participants, adding the element of contingent reinforcement to either the standard size print or enlarged print condition increased their WCPM. The enlarged print size alone condition only increased the WCPM for two participants; however, when enlarged print was combined with performance feedback or both performance feedback and contingent reinforcement, six participants demonstrated improved WCPM compared to the standard size print condition. These results suggest that combining stimulus change with consequences may improve oral reading fluency skills of students at-risk of reading failure.
\end{abstract}

\section{Keywords}

Fluency, Reading, Reinforcement, Feedback, Curriculum-Based Measurement

\section{Introduction}

Reading fluently is a critical life skill that is important for not only everyday life, 
but also for academic success. Individuals with low reading skills are more likely to experience feelings of inadequacy, low self-esteem, and higher levels of anxiety (Maughan \& Carroll, 2006; Panagiotis et al., 2008). Beyond direct reading instruction, teachers and school administrators are continuously seeking ways to assist students in improving their academic performance and making appropriate accommodations to facilitate success in the classroom. A review of research suggests that changing the visual stimuli of the printed material, more specifically, the size of the text, providing reinforcement, and utilizing performance feedback may provide the extra support students at risk of reading failure need to be successful in school (e.g., Alber-Morgan et al., 2007; O'Brien et al., 2005; Wilkins et al., 2009; Eckert et al., 2002; Eckert et al., 2006).

Multiple studies have examined the effects of print size and spacing on reading for individuals with low vision (e.g., Atiigan, Xiong, \& Legge, 2020; Bailey et al., 2003; Feely et al., 2005; Koenig \& Ross, 1991; Lueck et al., 2003; Ujima, 2010); however, fewer studies have explored the effects of print size on students without visual impairments and at-risk of reading failure (e.g., O'Brien et al., 2005; Wilkins et al., 2009). O'Brien et al. (2005) examined the effects of print size on students in grades 2 to 4 with dyslexia and students in grades 1 to 3 without dyslexia. The study found that generally for slower non-dyslexic readers, a larger print size was needed to help students reach their optimal reading speed. However, it was also determined that for non-dyslexic readers, critical print size decreased with age. Wilkins et al. (2009) presented two studies that explored the effects of print size and two studies that explored the effects of print design on the reading speed and comprehension of students ages 7 through 9 years. When print size increased on the Speed and Capacity of Language-Processing Test (Baddley et al., 1992), students demonstrated an increase in reading speed and comprehension. When print size was decreased on the Salford Sentence Reading Test (Bookbinder et al., 2002), students demonstrated a decrease in reading age.

Performance feedback and contingent reinforcement are behavioral strategies that can not only reap behavioral benefits for students, but also academic benefits. Contingent reinforcement, rooted in applied behavior analysis, involves providing reinforcement for each occurrence of an identified target behavior and performance feedback is "information a person receives about a particular aspect of his or her behavior following its completion" (Cooper et al., 2007: p. 262). Multiple studies have explored the effects of performance feedback and/or contingent reinforcement on reading skill development (e.g., Alber-Morgan et al., 2007; Eckert et al., 2002; Eckert et al., 2006; Hilsmer et al., 2016). Used in isolation or in combination, contingent reinforcement and performance feedback have resulted in positive reading outcomes for students (Alber-Morgan et al., 2007; Eckert et al., 2002; Eckert et al., 2006; Hilsmer et al., 2016).

A study by Hilsmer et al. (2016) evaluated the effects of reading interventions with and without contingent reinforcement and performance feedback on four middle school students' reading rate, accuracy, and comprehension skills. At the 
conclusion of the study, all four participants demonstrated an increase in reading rate compared to baseline when the Read-Model-Read (RMR) intervention was implemented, and three participants demonstrated an average increase in reading rate when the RMR intervention was combined with performance feedback and contingent reinforcement.

A repeated reading intervention, a brief prediction strategy, and systematic error correction and performance feedback were studied to determine their effectiveness for improving the reading fluency and comprehension skills of four middle-school students (Alber-Morgan et al., 2007). For three students, repeated readings with error correction and performance feedback resulted in an increased reading rate. For all four students, repeated readings with error correction and performance feedback resulted in a decrease in reading errors and improved comprehension.

Eckert et al. (2002) used a brief experimental analysis to evaluate the effects of an antecedent intervention, performance feedback, and/or contingent reinforcement on students' oral reading fluency. The study found that four of the six students benefited most from a combined treatment approach of the antecedent intervention with both performance feedback and contingent reinforcement. In addition, one participant benefited most from an antecedent intervention with contingent reinforcement and one participant benefited equally from all interventions.

Although previous studies have examined the components (print size, contingent reinforcement, and performance feedback) separately, no studies have been conducted that have examined these variables in various combinations. The current study sought to replicate some components of the brief experimental analysis study by Eckert et al. (2002) and evaluate the effectiveness of enlarged visual stimuli (increased font size), contingent reinforcement, performance feedback, and a combination of preceding factors on second- and third-grade students' oral reading fluency skills.

\section{Methods}

\subsection{Participants}

Participants for the study were seven (two female and five male) elementary school students ages seven and eight years old. Six of the participants were enrolled in second grade and one student was enrolled in third grade at the time of study completion. Convenience sampling was used, and all participants were identified for the study due to parent or teacher reports of below average reading skills. Additionally, participants were selected by utilizing three rural school districts, which the researchers had past work and/or affiliations. An attempt to secure at least 10 consent forms was made; however, only seven forms were signed and returned.

At the time of study completion, all participants were receiving instruction via a face-to-face learning format in three different small, rural public school dis- 
tricts in Pennsylvania. District enrollment ranged from approximately $1000 \mathrm{stu}-$ dents to 1400 students in grades kindergarten through 12 with about $40 \%$ of the student population receiving free/reduced lunch (Pennsylvania Department of Education, 2021). The school districts' population included $95.4 \%$ to $98.7 \%$ white, $1.5 \%$ to $1.6 \%$ Hispanic, $1.5 \%$ multiracial, and $1.1 \%$ black. The special education population ranged from $17.0 \%$ to $18.6 \%$ (Pennsylvania Department of Education, 2020).

As shown in Table 1, the demographic characteristics for each participant are displayed. Student A was an eight-year-old, second grade male student. Student $\mathrm{B}$ was an 8-year-old, second grade female student who received Title I reading services. Student $C$ was an 8 -year-old, third grade male student who had a diagnosis of Attention Deficit/Hyperactivity Disorder (ADHD) and received Title I reading services. Student D was an 8-year-old, second grade female student who received Title I reading services. Student E was an 8-year-old, second grade male student who received Title I reading services. Student E was a seven-year-old, male student who received special education services as a student with a Specific Learning Disability (SLD) in reading. Student F was an 8-year-old, second grade male student who was identified for special education services as a student with a SLD. Students A through E received all academic instruction in the general education setting, while students $F$ and $G$ received special education services for reading and all other instruction in the general education setting. All participants were

Table 1. Summary participant demographics.

\begin{tabular}{ccc}
\hline Characteristics & \multicolumn{2}{l}{ Participant Sample } \\
\cline { 2 - 3 } Sex & $\boldsymbol{n}$ & $\%$ \\
Male & 5 & $71 \%$ \\
Female & 2 & $29 \%$ \\
Grade & & \\
Second & 6 & $86 \%$ \\
Third & 1 & $14 \%$ \\
Age & & \\
7 & 1 & $14 \%$ \\
8 & 6 & $86 \%$ \\
Special Education Support & & \\
Yes & & \\
No & 2 & $71 \%$ \\
Reading Support & 5 & \\
Yes & & $57 \%$ \\
No & &
\end{tabular}


identified by their parents or teachers as having reading skill deficits. Only two participants received modified curriculum in reading/language arts. Each student completed testing sessions in a quiet area, free from distractions. Testing sessions were conducted over a two-week period; throughout the sessions, students were seated in a room with the researcher at a small table with only the reading passages in their line of sight.

\subsection{Measures}

To verify parent or teacher recommendation, as well as to determine oral reading fluency (ORF) baseline levels, each participant was given the Oral Reading Fluency subtest from the Wechsler Individual Achievement Test, Third Edition (WIAT-III) and Acadience Reading Oral Reading Fluency (ORF) passages (Good III et al., 2011b; Wechsler, 2009). The WIAT-III ORF subtest reliability, specific for those 7- and 8-year-old, was found to be 0.92 for ORF, 0.83 for Oral Reading Accuracy, and 0.89 for Oral Reading Rate (Breaux, 2009). A Survey Level Assessment was conducted with each participant to determine instructional level using Acadience Reading ORF passages. Each Survey Level Assessment followed the procedures outlined by Hosp, Hosp, and Howell (2007). All participants were initially given three grade-level ORF passages from Acadience Reading. If the student was in third grade and was able to read a median of 70 to 100 words correct per minute (WCPM) with six or fewer errors, the instructional reading level was determined to be at third grade. If the participant read less than $70 \mathrm{WCPM}$, the researcher then administered the Acadience Reading second grade ORF probes. For the second-grade probes, the student was required to read at least 40 WCPM with four or fewer errors. If less than 40 WCPM or more than four errors were observed, the participant was then administered the first-grade level probes (Hosp, Hosp, \& Howell, 2007). The same procedures were followed for students enrolled in second grade; however, the researchers started with second grade Acadience Reading passages and reversed to first grade passages if the student read less than $40 \mathrm{WCPM}$ or made more than four errors. If the student read less than $40 \mathrm{WCPM}$ or had more than four errors when given a first-grade passage, Acadience Reading benchmark recommendations were used to determine if the student should remain in the study.

In addition, all participants were given a Forced-Choice Reinforcement Menu. The results of the Forced-Choice Reinforcement Menu were used to determine each participant's reinforcement preferences in the areas of adult approval, competitive approval, peer approval, independent rewards, and/or consumable rewards (Gable, 1991). The Forced-Choice Reinforcement Menu provided each participant with a series of pairs of reinforcement options. The participant then chose which reinforcer they would prefer in each pair. A total of 40 pairs of reinforcement options were presented to each student. For each participant, the top three areas of reinforcement identified by the Forced-Choice Reinforcement Menu are presented in Table 2. 
As shown in Table 3, participants' standard scores and grade equivalent scores on the ORF subtest of the WIAT-III all fell within the below average range. Furthermore, grade equivalent scores ranged from 1.1 to 1.5 years below their current grade levels respectively. Survey Level Assessment results indicated that all students' scores fell within the instructional level when given first- or second-grade level probes. When given three second-grade level Acadience Reading ORF probes, Student A read a median of 59 words correct per minute with $93 \%$ accuracy, Student B read a median of 47 WCPM with 98\% accuracy, Student C read a median of 54 WCPM with 93\% accuracy, Student D read a median of 45 WCPM with 96\% accuracy, and Student E read 42 WCPM with $95 \%$ accuracy. When given three first-grade level Acadience Reading ORF probes, Student F read 25 WCPM with 68\% accuracy, and Student G read 47 WCPM with $94 \%$ accuracy. Although Student F did not meet the instructional level criteria recommended by Hosp, Hosp, and Howell (2007), the researcher was not able to administer kindergarten level passages, because Acadience Reading does

Table 2. Forced-choice reinforcement menu results.

\begin{tabular}{cccc}
\hline \multirow{2}{*}{ Participant } & \multicolumn{3}{c}{ Forced-Choice Reinforcement Menu Results } \\
\cline { 2 - 4 } & First Choice & Second Choice & Third Choice \\
\hline A & Independent Rewards & Peer Approval & Competitive Approval \\
B & Independent Rewards & Consumable Rewards & Peer Approval \\
C & Adult Approval & Consumable Rewards & Competitive Approval \\
D & Independent Rewards & Adult Approval & Consumable Rewards \\
E & Independent Rewards & Consumable Rewards & Peer Approval \\
F & Peer Approval & Competitive Approval & Independent Rewards \\
G & Adult Approval & Independent Rewards & Consumable Rewards \\
\hline
\end{tabular}

Table 3. Criteria for inclusion and baseline results.

\begin{tabular}{cccc}
\hline & \multicolumn{3}{c}{ Criteria for Inclusion } \\
\cline { 2 - 4 } Participant & \multicolumn{3}{c}{ WIAT-III Oral Reading Fluency } \\
Results & $\begin{array}{c}\text { Survey Level Assessment - } \\
\text { Instructional Level }\end{array}$ \\
\cline { 2 - 4 } & SS & GE & Grade \\
\hline A & 82 & 1.1 & 2 \\
B & 77 & 1.4 & 2 \\
C & 84 & 2.0 & 2 \\
D & 76 & 1.3 & 2 \\
E & 78 & 1.3 & 1 \\
F & 80 & 1.2 & 1 \\
G & 84 & 1.4 & 2 \\
\hline
\end{tabular}


not publish kindergarten level ORF probes. Since Student F read 25 WCPM, which falls within the benchmark range for a mid-year first grade student based on Acadience Reading benchmark recommendations, Student F remained in the study and was administered first grade level probes.

\subsection{Reliability and Validity of Outcome Measures}

Acadience Reading ORF passages were used to measure each participant's level of reading fluency under each condition. Results were recorded as words correct per minute (WCPM). Acadience Reading publishes both standard size print and enlarged print ORF passages (Good III et al., 2011b, 2011c). Reliability for Acadience Reading first grade ORF passages ranged from 0.95 to 0.99 , from 0.90 to 0.99 for second grade, and from 0.92 to 0.99 for third grade (Dewey et al., 2015; Good III et al., 2019). Acadience Reading predictive and concurrent validity for first grade ORF passages ranged from 0.64 to 0.75 , from 0.73 to 0.76 for second grade, and from 0.66 to 0.67 for third grade (Dewey et al., 2015; Good III et al., 2019).

\subsection{Response Measurement and Reliability}

The researchers monitored procedural integrity throughout the study using fidelity checklists and interobserver agreement to ensure standardization and consistency across participants. Procedural integrity was 100\% for all participants in the delivery of instructions for baseline and treatment material, presentation of reading passages, accuracy of timing readings, and delivery of performance feedback and contingent reinforcement. In addition, each session was audio recorded to determine interrater agreement and ensure reliability of data collected. Interobserver agreement was collected for $50 \%$ of the sessions for each participant and was determined to be $97 \%$.

Participant results were recorded on the researcher's copy of the Acadience Reading ORF probes. With each presented passage, participants were instructed to read aloud for one minute. Participants began reading with the first word of each passage with errors being noted on the record form. At the end of the one-minute timing, the researcher inserted a closed bracket or parentheses following the last word read. The researcher counted the total number of words read and the total number of errors. The number of errors were then subtracted from the total words read to determine each participant's overall words read correct per minute (WCPM). Scoring followed recommendations in the Acadience Reading K-6 Assessment Manual (Good III et al., 2011a). A word was counted as correct if the student read the word correctly or self-corrected a word within three seconds of the error. Words counted as errors included words read incorrectly, substitutions, skipped words, words not read within three seconds, words read out of order, and segmented words not read as whole words. Errors were denoted by a slash through the word with the substitution words recorded and omissions with a slash only (Good III et al., 2011a). 


\section{Procedures}

Once the WIAT-III Oral Reading Fluency subtest, the Survey Level Assessment, and the Forced-Choice Reinforcement Menu were administered, the experimental sessions were initiated. Sessions for each participant lasted approximately 15 minutes and took place over a two-week period. An alternating-treatment designed was implemented to collect data. Instructions for each Oral Reading Fluency (ORF) passage were delivered according to the Acadience Reading K-6 Assessment Manual (Good III et al., 2011a). Each researcher stated, "Now read this story to me. Please do your best reading. Ready, begin" (Good III et al., 2011a: p. 90). Since all participants were familiar with oral reading passages, the researchers agreed the shortened directions were adequate. The timer was started as soon as the student started reading the first word of the passage. If a participant paused for 3 seconds, the researcher provided the word to the student. Scoring was followed using the procedures outlined in the Acadience Reading K-6 Assessment Manual (Good III et al., 2011a).

\subsection{Standard Size Print Condition (SS)}

During this condition, no intervention was provided. Each researcher presented the standard size print Acadience Reading ORF passage to the participant and proceeded with the directions to read the ORF passage.

\subsection{Standard Size Print Condition and Performance Feedback (SS + PF)}

The researcher showed the participant the graph with his/her baseline median score graphed (from the Survey Level Assessment results). The researcher proposed a goal (an increase from $1 \%$ to $5 \%$ from baseline) to the participant to consider. If the participant was agreeable, the researcher proceeded with the directions to read the ORF passage. If the participant did not agree with the goal, the examiner and the student modified the goal until an agreed upon goal was reached. At the end of the CBM administration, the examiner and participant graphed the results together and verbal feedback was provided.

\subsection{Standard Size Print Condition and Contingent Reinforcement (SS + CR)}

The researcher provided the participant with a pre-determined goal (an increase of $4 \%$ to $5 \%$ from the Survey Level Assessment results) and shared this goal with the participant. The examiner informed the participant that if the pre-determined goal was achieved, he/she would receive the preferred reinforcement. Then, the researcher proceeded with the directions to read the ORF passage. If the participant met the goal, the examiner delivered the reinforcement. Reinforcement was specific to each participant based on the results of the Forced-Choice Reinforcement Menu (Cartwright \& Cartwright, 1970; Gable, 1991). 


\subsection{Standard Size Print Condition, Performance Feedback, and Contingent Reinforcement (SS + PF + CR)}

The researcher shared the graph of progress with the student, provided the participant with a pre-determined goal (an increase of $4 \%$ to $5 \%$ from baseline), and shared the goal with the student. If the student did not agree with the goal, the researcher and the student modified the goal until an agreed upon goal was reached. The researcher informed the student that if the pre-determined goal was achieved, he/she would receive the preferred reinforcement. Then the researcher proceeded with the directions to read the ORF passage. The researcher and participant graphed the results together, and if the participant met the goal, the examiner delivered the reinforcement. Reinforcement was specific to each student based on the results of the Forced-Choice Reinforcement Menu (Cartwright \& Cartwright, 1970; Gable, 1991).

\subsection{Enlarged Size Print Condition (ES)}

During this condition, the researcher presented the enlarged print passage from Acadience Reading to the participant and proceeded with the directions to read the ORF passage.

\subsection{Enlarged Size Print Condition and Performance Feedback (ES + PF)}

The researcher showed the participant the graph with his/her baseline median score graph (from the Survey Level Assessment results). The researcher proposed a goal (an increase from $1 \%$ to $5 \%$ of from baseline) to the participant to consider. If the participant was agreeable, the researcher proceeded with the directions to read the enlarged print ORF passage. If the participant did not agree with the goal, the examiner and the participant modified the goal until an agreed upon goal was reached. At the end of the CBM administration, the examiner and participant graphed the student's results together and feedback was provided.

\subsection{Enlarged Size Print Condition and Contingent Reinforcement (ES + CR)}

The researcher provided the student with a pre-determined goal (an increase of $4 \%$ to 5\% from Survey Level Assessment results) and shared this goal with the student. The researcher informed the student that if the pre-determined goal was achieved, he/she would receive the preferred reinforcement. Then, the researcher proceeded with the directions to read the enlarged print ORF passage. If the participant met the goal, the researcher delivered the reinforcement. Reinforcement was specific to each participant based on the results of the Forced-Choice Reinforcement (Cartwright \& Cartwright, 1970; Gable, 1991).

\subsection{Enlarged Size Print Condition, Performance Feedback, and Contingent Reinforcement (ES + PF + CR)}

The researcher shared the graph of progress with the participant, provided the 
student with a pre-determined goal (an increase of $4 \%$ to $5 \%$ from baseline), and shared the goal with the student. If the participant did not agree with the goal, the examiner and the student modified the goal until an agreed upon goal was reached. The examiner informed the student that if the pre-determined goal was achieved, he/she would receive the preferred reinforcement. Next, the researcher proceeded with the directions to read the enlarged print ORF passage. The researcher and participant graphed the results together, and if the participant met the goal, the examiner delivered the reinforcement. Reinforcement was specific to each participant based on the results of the Forced-Choice Reinforcement (Cartwright \& Cartwright, 1970; Gable, 1991).

\subsection{Experimental Design}

A brief experimental analysis using an alternating treatment design was used. A brief experimental analysis was chosen based on prior research that has used brief experimental analyses to evaluate the effectiveness of reading interventions (e.g., Daly III et al., 2006; Eckert et al., 2002; Petursdottir et al., 2009). For this study, the conditions were presented in a randomized order with each condition occurring twice per participant throughout the study. A self-report fidelity checklist was used by the researcher to ensure consistency across participants. Additionally, all sessions were audio recorded to verify data collected through interobserver agreement.

\section{Results}

Figure 1 displays the participants' WCPM during the baseline (i.e., standard size print [SS]) and treatment conditions.

\subsection{ES Conditions}

When examining results, five participants averaged more WCPM when performance feedback (PF) was added to the enlarged size print condition (ES). An effect size of $d=0.476$ was calculated using Cohen's $d$ formula. According to Cohen (1988), $d=0.2$ is considered a small effect size, $d=0.5$ is considered a medium effect size, and $d=0.8$ is considered a large effect size. Four participants averaged more WCPM when contingent reinforcement (CR) was added to the ES condition, which resulted in an effect size of $d=0.119$. When both PF and CR were added to the ES condition, six participants averaged more WCPM when compared to the ES only condition and resulted in an effect size of $d=$ 0.516 .

\subsection{SS Conditions}

When examining results, five participants averaged more WCPM when PF was added to the SS condition. An effect size of $d=0.460$ was calculated using Cohen's $d$ formula. Six participants averaged more WCPM when CF was added to the SS condition, which resulted in an effect size of $d=0.582$. When both PF and 
CR were added to the SS condition, three participants averaged more WCPM compared to the SS only condition and resulted in an effect size of $d=0.242$.

\subsection{ES vs. SS Conditions}

When the ES condition was compared to the SS condition, only two participants demonstrated an average increase in WCPM. Cohen's $d$ effect size was calculated at $d=0.058$. When the $\mathrm{ES}+\mathrm{PF}$ condition was compared to the SS + PF condition, three participants demonstrated an average increase in WCPM. Cohen's $d$ effect size was calculated at $d=0.049$. When the ES + CF condition was
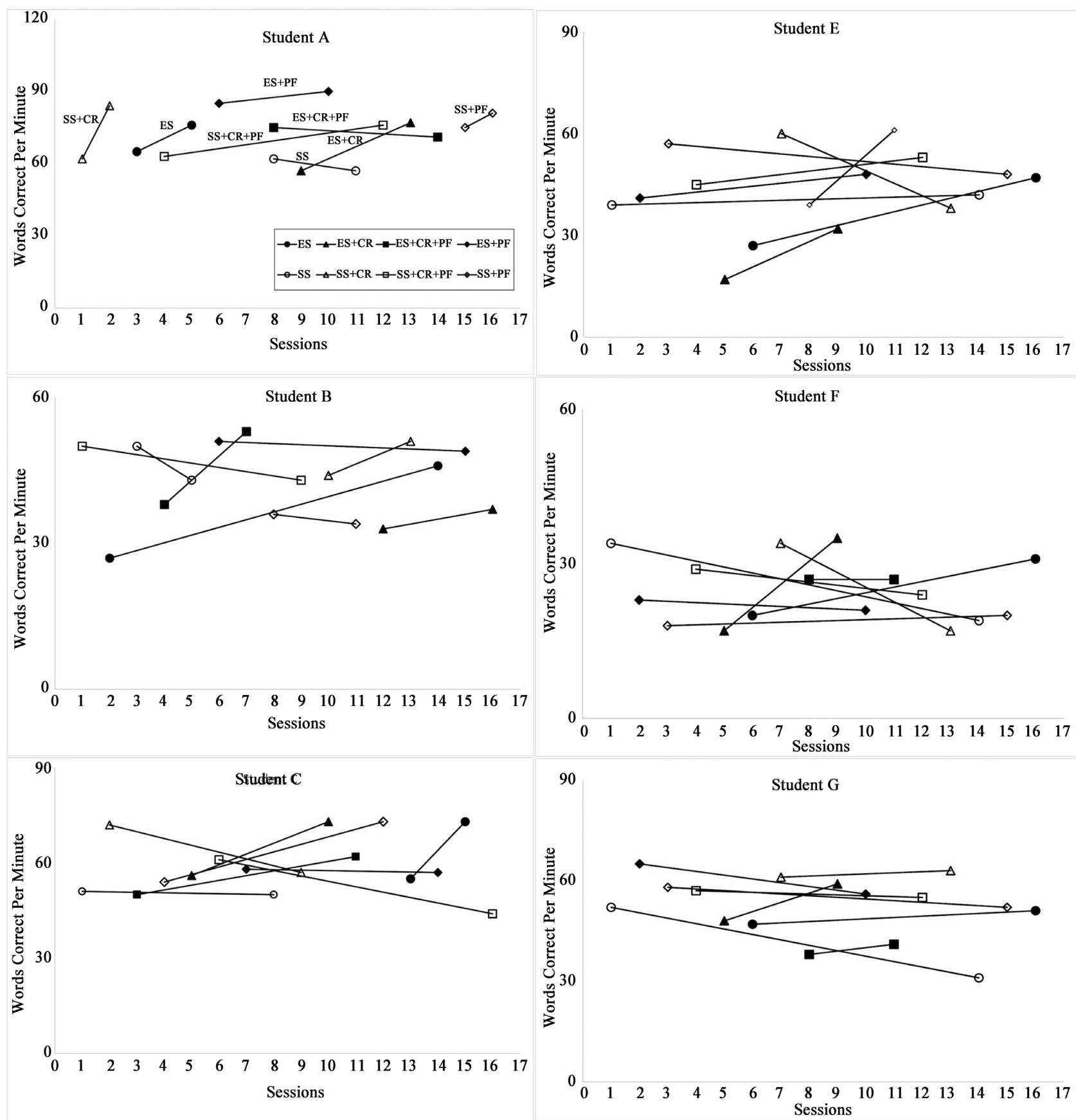


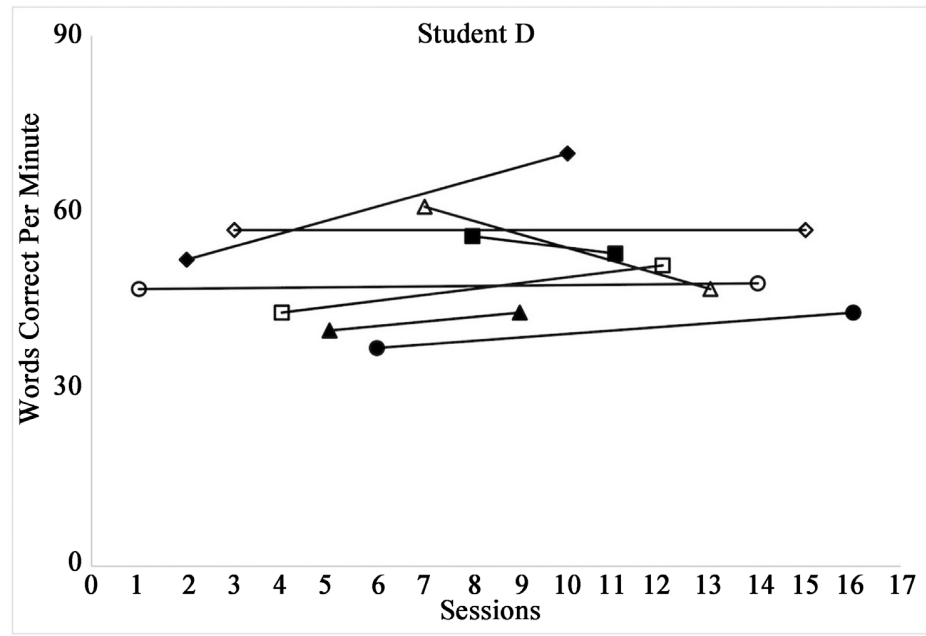

Note SS = standard size print (baseline), ES = enlarged size print, $\mathrm{SS}+\mathrm{PF}=$ standard size print and performance feedback, $\mathrm{ES}+\mathrm{PF}=$ enlarged size print and performance feedback, $\mathrm{SS}+\mathrm{CR}=$ standard size print and contingent reinforcement, $\mathrm{ES}+\mathrm{CR}=$ enlarged size print and contingent reinforcement, $\mathrm{SS}+\mathrm{PF}+\mathrm{CR}=$ standard size print, performance feedback, and contingent reinforcement, $E S+P F+C R=$ enlarged size print, performance feedback, and contingent reinforcement.

Figure 1. WCPM across experimental conditions for students A through G.

compared to the SS + CF condition, only one participant demonstrated an average increase in WCPM and one participant exhibited no difference in average WCPM. The ES + CF condition compared to the SS + CF condition resulted in an effect size of $d=0.665$. When the $\mathrm{ES}+\mathrm{PF}+\mathrm{CR}$ condition was compared to the $\mathrm{SS}+\mathrm{PF}+\mathrm{CR}$ condition, six participants demonstrated an increase in average WCPM, which resulted in an effect size of $d=0.327$.

\subsection{CR Conditions}

When comparing the average WCPM for both ES and SS only conditions to the average WCPM for both ES + CR and SS + CR, six participants averaged more WCPM when CR was added. This resulted in an effect size of $d=0.260$ for the CR condition.

\subsection{PF Conditions}

When comparing the average WCPM for both ES and SS only conditions to the average WCPM for both ES + PF and SS + PF, five participants averaged more WCPM when CR was added. This resulted in an effect size of $d=0.050$ for the $\mathrm{PF}$ condition.

\subsection{CR + PF Conditions}

When comparing the average WCPM for both ES and SS only conditions to the average WCPM for both ES + PF + CR and SS + PF + CR, six participants averaged more WCPM when both $\mathrm{CR}+\mathrm{PF}$ were added. This resulted in an effect size of $d=0.455$ for the $\mathrm{PF}+\mathrm{CR}$ condition. 


\subsection{Social Validity}

Following the completion of the study, social validity was evaluated with a brief three question survey to determine participants' thoughts and feelings about the study. Participants rated each statement from one to three, with one being disagree to three being agree. A one rating was correlated with a frown face, a two rating was correlated with a neutral face, and a three rating was correlated with a smiley face. The total possible score for each participant was nine. Based on the ratings of all seven participants, a mean score of 7.4 was obtained, indicating a high level of acceptability.

\section{Discussion}

Results of this study suggest that incorporating elements of enlarged print, contingent reinforcement, and performance feedback are useful for improving students' ORF skills, specifically their WCPM. For six out of the seven participants, adding the element of performance feedback or adding the elements of both performance feedback and contingent reinforcement enhanced their oral reading fluency skills. For five participants, adding the element of contingent reinforcement to either standard size print or enlarged print enhanced their ORF skills. Enlarged print size alone only enhanced two participants' oral reading fluency skills; however, when enlarged print size was combined with performance feedback or both performance feedback and contingent reinforcement, six participants demonstrated an increase in their average WCPM compared to the standard size print condition. For Students A and C, improvements in WCPM were observed in all seven conditions compared to the standard size print (baseline) condition. For Students D and G, improvements in WCPM were observed in four conditions compared to the standard size print (baseline) condition. For Student E, improvements in WCPM were observed in five conditions compared to the standard size print (baseline) condition. For Students B and H, improvements were only observed in one to two conditions compared to the standard size print (baseline) condition.

There were several limitations that existed within the current research study. Research limitations are characteristics that exist within the areas of the study that can alter the interpretation of the findings or analysis from the research (Tracy, 2019). Typically, limitations exist because of the participants, study methodology, restrictions surrounding how generalizable the results may be, and unidentified sources of variability among results. The small sample size $(n=7)$, as well as the characteristics of the participants, makes the current study difficult to generalize to the entire population of at-risk readers. The current sample did not include a diverse population of participants since $100 \%$ of participants were identified as white, attended rural school districts in Pennsylvania, and were 7to 8-years old. The findings may only be generalized to students of similar age and backgrounds.

Another limitation of the current study involves the limited prior research on 
changing the visual stimuli of the ORF passages, utilizing contingent reinforcement, and giving performance feedback for the improvement of students' reading fluency skills. Although these elements have not been studied in combination, the previous research that examined some of the various components, in isolation or in combination, have generally demonstrated positive outcomes for students (e.g., Eckert et al., 2002; Hilsmer et al., 2016; Wilkins et al., 2009). The enlarged print size condition only had a positive effect for two participants, but it increased the average WCPM by over ten words for both of these participants. Furthermore, these two participants had the highest baseline scores.

Finally, unidentified sources of variability may have influenced results, thus limiting the reliability of the study. Although the Forced-Choice Reinforcement Menu (Cartwright \& Cartwright, 1970; Gable, 1991) was used to identify categories of reinforcement for each participant, for some participants the highest rated reinforcement category posed challenging for this study. For example, for participant F, peer approval received the highest rating, but due to the environmental conditions of the study, peer approval could not be offered. In addition, for participant $\mathrm{C}$ and $\mathrm{G}$, adult approval was identified as the highest rated category. This could have skewed results because of the overlap between the selected reinforcement and the performance feedback condition.

\section{Conclusion}

The results of this study extend previous research by evaluating the elements of increased print size, performance feedback, and/or contingent reinforcement on students' oral reading rate. For five participants, increases in their average WCPM compared to baseline were observed in at least four of the seven treatment conditions. These findings are important because teachers can utilize elements of enlarged print size, performance feedback, and/or contingent reinforcement to enhance students' oral reading fluency skills within the classroom. All of these strategies are simple to implement and may maximize student reading potential. Using a brief experimental analysis approach can assist teachers in determining the most effective strategies for their students and consequently, making informed instructional decisions. Future research should include replication using a more individualized preference assessment. Furthermore, additional benefits to the field of education may be gained by increasing the sample size and demographic sample of participants. A larger, more diverse sample size would allow for a more generalizable, reliable, in-depth analysis of results. Finally, further research is recommended to determine if enlarged print size alone is an effective intervention for students with a slight risk of reading failure and more specifically for students with initially higher baseline reading rates.

\section{Conflicts of Interest}

The authors declare no conflicts of interest regarding the publication of this paper. 


\section{References}

Alber-Morgan, S. R., Ramp, E. M., Anderson, L. L., \& Martin, C. M. (2007). Effects of Repeated Readings, Error Correction, and Performance Feedback on the Fluency and Comprehension of Middle School Students with Behavior Problems. Journal of Special Education, 41, 17-30. https://doi.org/10.1177/00224669070410010201

Atiigan, N., Xiong, Y. Z., \& Legge, G. E. (2020). Reconciling Print-Size and Display-Size Constraints on Reading. PNAS Proceedings of the National Academy of Sciences of the United States of America, 117, 30276-30284. https://doi.org/10.1073/pnas.2007514117

Baddley, A. D., Emslie, H., \& Nimmo-Smith, M. I. (1992). The Speed and Capacity of Language Processing Task: SCOLP. Thames Valley Test Company.

Bailey, I. L., Lueck, A. H., Greer, R. B., Tuan, K. M., Bailey, V. M., \& Dornbusch, H. G. (2003). Understanding the Relationships between Print Size and Reading in Low Vision. Journal of Visual Impairment \& Blindness, 97, 325. https://doi.org/10.1177/0145482X0309700602

Bookbinder, G. E., Vincent, D., \& Crumpler, M. (2002). Salford Sentence Reading Test (Revised). Hodder Education.

Breaux, K. L. (2009). WIAT-III Technical Manual. Pearson.

Cartwright, C. A., \& Cartwright, G. P. (1970). Determining the Motivational Systems of Individual Children. TEACHING Exceptional Children, 2, 143-149. https://doi.org/10.1177/004005997000200311

Cohen, J. (1988). Statistical Power Analysis for the Behavioral Sciences. Routledge Academic.

Cooper, J. O., Heron, T. E., \& Heward, W. L. (2007). Applied Behavior Analysis (2nd ed.). Pearson.

Daly III, E. J., Andersen, M., Gortmaker, V., \& Turner, A. (2006). Using Experimental Analysis to Identify Reading Fluency Interventions: Connecting the Dots. The Behavior Analysis Today, 7, 133-150. https://doi.org/10.1037/h0100147

Dewey, E. N., Powell-Smith, K. A., Good III, R. H., \& Kaminski, R. A. (2015). Acadience Reading K-6 Technical Adequacy Brief. Acadience Learning. https://acadiencelearning.org/wp-content/uploads/2020/01/Acadience Reading_Techn ical Adequacy Brief.pdf

Eckert, T. L., Ardoin, S. P., Daly, E. J., \& Martins, B. K. (2002). Improving Oral Reading Fluency: A Brief Experimental Analysis of Intervention with Consequences. Journal of Applied Behavior Analysis, 35, 271-281. https://doi.org/10.1901/jaba.2002.35-271

Eckert, T. L., Dunn, E. K., \& Ardoin, S. P. (2006). The Effects of Alternate Forms of Performance Feedback on Elementary-Aged Students' Oral Reading Fluency. Journal of Behavioral Education, 15, 148-161. https://doi.org/10.1007/s10864-006-9018-6

Feely, M., Rubin, G. S., Ekstrom, K., \& Perera, S. (2005). Investigation into Font Characteristics for Optimum Reading Fluency in Readers with Sight Word Problems. International Congress Series, 1282, 530-533. https://doi.org/10.1016/j.ics.2005.05.121

Gable, R. A. (1991). Forced-Choice Reinforcement Menu. https://pbisworld.com/wp-content/uploads/Forced-Choice-Reinforcement-Menu.pdf

Good III, R. H., Kaminski, R. A., Cummings, K., Dufour-Martel, C., Petersen, K., Powell-Smith, K. A., Stollar, S., \& Wallin, J. (2011a). Acadience Reading K-6 Assessment Manual. Acadience Learning, Inc. https://acadiencelearning.org/wp

Good III, R. H., Kaminski, R. A., Cummings, K., Dufour-Martel, C., Petersen, K., Powell-Smith, K. A., Stollar, S., \& Wallin, J. (2011b). Acadience Reading Oral Reading Fluency Student Materials. Acadience Learning, Inc.

https://acadiencelearning.org/acadience-reading-materials-download 
Good III, R. H., Kaminski, R. A., Cummings, K., Dufour-Martel, C., Petersen, K., Powell-Smith, K. A., Stollar, S., \& Wallin, J. (2011c). Acadience Reading Oral Reading Fluency Student Materials: Large Print. Dynamic Measurement Group, Inc. https://acadiencelearning.org/acadience-reading-materials-download/content/uploads/ 2020/08/AcadienceReading ALO Assessment Manual.pdf

Good III, R. H., Kaminski, R. A., Dewey, E. N., Wallin, J., Powell-Smith, K. A., \& Latimer, R. (2019). Acadience Reading K-6 Technical Manual. https://acadiencelearning.org/wp-content/uploads/2020/01/Acadience Reading K-6 T echnical Manual.pdf

Hilsmer, A. S., Wehby, J. H., \& Falk, K. B. (2016). Reading Fluency Interventions for Middle School Students with Academic and Behavioral Disabilities. Reading Improvement, 53, 53-64.

Hosp, M. K., Hosp, J. L., \& Howell, K. W. (2007). The ABCs of CBM: A Practical Guide to Curriculum-Based Measurement. Guilford Press.

Koenig, A. J., \& Ross, D. B. (1991). A Procedure to Evaluate the Relative Effectiveness of Reading in Large and Regular Print. Journal of Visual Impairment and Blindness, 85, 198-204. https://doi.org/10.1177/0145482X9108500503

Lueck, A. H., Bailey, I. L., Greer, R. B., Tuan, K. M., Bailey, V. M., \& Dornbusch, H. G. (2003). Exploring Print-Size Requirements and Reading for Students with Low Vision. Journal of Visual Impairment \& Blindness, 97, 335-354. https://doi.org/10.1177/0145482X0309700603

Maughan, B., \& Carroll, J. (2006). Literacy and Mental Disorders. Current Opinion in Psychiatry, 4, 350-354. https://doi.org/10.1097/01.yco.0000228752.79990.41

O’Brien, B. A., Mansfield, S. J., \& Legge, G. E. (2005). The Effect of Print Size on Reading Speed in Dyslexia. Journal of Research in Reading, 28, 332-349. https://doi.org/10.1111/j.1467-9817.2005.00273.x

Panagiotis D., Gardelis, J., Ventouri, K., Nikolaou, K., Koltsida, G., Tsitoura, S., \& Constantopoulos, A. (2008). Behavior Problems in Children with Learning Difficulties According to Their Parents and Teachers. Pediatrics, 121, S100.

https://doi.org/10.1542/peds.2007-2022CC

Pennsylvania Department of Education (2020). Special Education Data Reporting. https://penndata.hbg.psu.edu/Public-Reporting/Data-at-a-Glance

Pennsylvania Department of Education (2021). Public School Enrollments 2020-2021. https://www.education.pa.gov/DataAndReporting/Enrollment/Pages/PublicSchEnrRep orts.aspx

Petursdottir, A. L., McMaster, K., McComas, J. J., Bradfield, T., Braganza, V., Koch-McDonald, J., Rodriguez, R., \& Scharf, H. (2009). Brief Experimental Analysis of Early Reading Interventions. Journal of School Psychology, 4, 215-243.

https://doi.org/10.1016/j.jsp.2009.02.003

Tracy, S. J. (2019). Qualitative Research Methods: Collecting Evidence, Crafting Analysis, Communicating Impact (2nd ed.). Wiley.

Ujima, K. (2010). Selecting a Print Size Suitable for Readers with Low Vision. Japanese Journal of Special Education, 48, 323-331. https://doi.org/10.6033/tokkyou.48.323

Wechsler, D. (2009). Wechsler Individual Achievement Test (3rd ed.). Psychological Corporation.

Wilkins, A., Cleave, R., Grayson, N., \& Wilson, L. (2009). Typography for Children May Be Inappropriately Designed. Journal of Research in Reading, 32, 402-412.

https://doi.org/10.1111/j.1467-9817.2009.01402.x 